Trinity University

Digital Commons @ Trinity

School of Business Faculty Research

School of Business

$1-2019$

\title{
Texas Sport Leadership Consultants, LLC: A Case of Cases
}

Emily S. Sparvero

Randall J. Griffiths

Jacob K. Tingle

Trinity University, jtingle@trinity.edu

Follow this and additional works at: https://digitalcommons.trinity.edu/busadmin_faculty

Part of the Business Administration, Management, and Operations Commons

\section{Repository Citation}

Sparvero, E., Griffiths, R., \& Tingle, J. (2019). Texas sport leadership consultants, Ilc: A case of cases. Case Studies in Sport Management, 8(S1), S45-S49. doi:10.1123/cssm.2018-0033

This Post-Print is brought to you for free and open access by the School of Business at Digital Commons @ Trinity. It has been accepted for inclusion in School of Business Faculty Research by an authorized administrator of Digital Commons@ Trinity. For more information, please contact jcostanz@trinity.edu. 


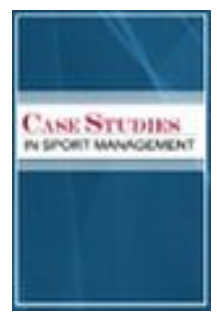

Texas Sport Leadership Consultants, LLC: A case of cases

\begin{tabular}{|r|l|}
\hline Journal: & Case Studies in Sport Management \\
\hline Manuscript ID & CSSM.2018-0033.R2 \\
\hline Manuscript Type: & Special Issue Case Study \\
\hline Keywords: & Power, Leadership, Group Dynamics, experiential learning cycle \\
\hline \multicolumn{2}{|l}{} \\
\hline
\end{tabular}

SCHOLARONE ${ }^{m}$

Manuscripts 
Texas Sport Leadership Consultants, LLC: A case of cases

Emily Sparvero, Randall Griffiths, and Jacob Tingle

Sparvero is with the University of Texas, Austin, TX. Griffiths is with the University of the Incarnate Word, San Antonio, TX. Tingle is with the Business Administration, Trinity University, San Antonio, TX. Sparvero (sparv@austin.utexas.edu) is corresponding author.

Running head: Texas Sports Leadership Consultants

This immersive, multi-case experience consists of four distinct cases and one meta-case that require students to engage with several organizational behavior topics. First, the meta-case takes the form of Texas Sport Leadership Consultants (TSLC), a fictitious company which consults with local sport management professionals in a variety of contexts. Students participate as temporary members of the company, using the classroom-as-organization model to analyze the issues and challenges associated with working as a member of TSLC. TSLC work groups are hired by four different clients, each of whom has a unique OB challenge. These clients include: (1) a combat-oriented sport company; (2) a company that provides luxury sport experiences for business travelers; (3) Division II athletic directors; and (4) a minor league hockey team. The clients face challenges related to mission and vision, group dynamics, change leadership, and power and politics. Student groups analyze the case and provide recommendations, which are presented as the basis for discussion among TSLC colleagues.

Keywords: Power, Leadership, Group Dynamics, experiential learning cycle

\section{Introduction}

Congratulations! As a student in this class, you will be working as a member of Texas Sport Leadership Consultants (TSLC), a consulting company owned by three sport management professors from three different universities. TSLC strives to engage and assist sport professionals throughout south and central Texas. Many of the clients come from personal connections that the three founding professors have formed over the past 25 years of working in 
the region. In true academic fashion, they want to ensure that any student that engages with the community is properly prepared with relevant theory and a quality preliminary analysis of the client's problems. They also require extensive reflection throughout the project.

You and your fellow students will be grouped into teams and asked to analyze the client cases brought by the program's founders. Clients will be serviced by only one team (although one team may service multiple clients), so before your instructor awards the clients to teams, each team will need to review relevant theory and practice essential to the primary problems of the case. Each team will then provide a preliminary analysis based on the limited information available prior to meeting directly with the client. Your course instructor will devise his or her own system for determining which team is best suited to engage the client. That team will then be "Gone to Texas" as they say.

\section{Case 1: Warrior Group International (WGI)}

At your first weekly TSLC meeting, one of the founding partners begins: "Our next client is a long-time friend of mine, Jack Hays of WGI. His daughters are pulling him in two different directions. He isn't sure what to do. He wants to be sure to leave a company intact and healthy for his daughters to run once they have a little more experience. He can't imagine them not working at WGI together. That means being competitive over the next $10-20$ years at least." Background information on WGI is provided below:

Jack Hays first came to Texas while serving in the army from 1968-1972. After finishing a one-year tour in Vietnam, Jack was stationed at Fort Sam Houston in San Antonio to train with the Modern Pentathlon group supported by the U.S. Army. During those three years he traveled with the team around the world, competing against other countries' Pentathlon teams. Although they were not the strongest competitors, Jack loved competing against the teams from Central 
and South America. These guys competed more for themselves than for their national team. $\mathrm{He}$ could see it in their eyes; each and every match was personal. Jack wanted to surround himself with people like this for the rest of his life.

It didn't take long for Jack to start WGI. Today, WGI is a company that buys out and operates combat-oriented sports companies, adding them to a broad portfolio of enterprises. It began in 1979 as a boxing promotions business, arranging fights throughout Texas, Mexico, and even one series in Panama (prior to the invasion). Although the fight promotion business was successful, Jack saw that several sports in this market could be even more lucrative. Over the years, WGI has added several combat related sport assets to its portfolio. From boxing promotions, he started his own boxing gym in 1982. After the Berlin Wall came down, he sponsored one Polish and three Russian fencing masters in clubs around south Texas. He has also added paintball, IDPA pistol competitions, an archery range, and four MMA gyms in the last few years.

WGI's competition had typically come in the form of single sport clubs. Usually owned and operated by one lead instructor, these clubs could never afford the overhead that Jack could maintain with his multi-club portfolio. WGI had the luxury of full-time staff dedicated to promotions, payroll, legal, and logistics. Sooner or later, these "one-man-band" operations got into trouble and Jack was ready to add them to the WGI portfolio.

New challenges. Lately, Jack has noticed some of his staff, including his youngest daughter Amanda, talking more about shifting toward what he calls "Soft-Cs" meaning knockoffs of combat sports. Activities like cardio kick-boxing had been around for a while, but now there were all of these "warrior" themed gyms, obstacle course runs, and boot-camp classes. Jack dismissed these comments about "Soft-Cs" until one day, his favorite MMA club was virtually 
empty. The lead trainer said most of the fighters were down at the traveling "Alpha Warrior" course that was in town for the weekend.

Jack wasn't quite sure what to make of this. He immediately called on his right and left hands at WGI. His two daughters, April and Amanda, had both grown up on the various gym floors and in its central office. Today these women each had degrees from the local university, wicked uppercuts, and had proven themselves to be Jack's most competent and trusted partners in the WGI extended family.

Unfortunately, April and Amanda didn't agree on what the future held for WGI. April felt that operations like Alpha Warrior were just passing trends. "The companies that run them are not in it for the long haul. As soon as profits start to dip, they pull the plug and it all goes away." Amanda, on the other hand, felt that this was the beginning of lasting competition in the combat sport market. "The people behind Alpha Warrior will replace it with something just as attractive to our fighters. The combat sport market is more mainstream than it was 20 years ago."

The debate between April and Amanda showed no sign of resolving soon. Each presented strong arguments for their perspective. Jack's notes captured as much as possible. April:

- $\quad$ Boxing has paid the bills around here for 30 years. It will for the next 30.

- That is not the business we are in.

- Those activities don't exist as independent clubs to buy up. We would have to start a new club.

- We don't know people in that industry.

- Larry Colson has been shooting in our club for 20 years and he will for the next 20 .

- Fencing is down but we have two Olympians in our local club. 
- What will the next thing be? Will you be threatened by that one as well?

Amanda:

- $\quad$ Alpha Warrior is riding the success of American Ninja Warrior which is on NBC.

- $\quad$ MMA is taking boxers; we are stealing from ourselves.

- $\quad$ Fencing is so small and not TV friendly. It will never contribute to the bottom line.

- $\quad$ Every gym out there has 20 cardio kick-boxing classes. Demand is high.

- If Alpha Warrior can take our fighters, something will come along and take our shooters too. We need to be proactive.

- We had to pass on buying that gym in Corpus Christi last month. Money is tight and we need the flexibility that this move can provide.

- $\quad$ Aurora, Sandy Hook, Sutherland Springs, Dayton, the El Paso Wal-Mart - Eventually we are going to lose our shooting business.

Your task. Your team will need to advise Jack about the future of WGI. Can Jack and his daughters develop a mission and vision for WGI that will remain true to WGI's roots and original conception and also keep Jack's family together? Your first step is to consider the mission and vision of WGI based on the facts presented in this case. In addition to recommendations for WGI's mission and vision, the final recommendation to Jack would be strengthened by a description of the industry sector, potential barriers to entry, a SWOT analysis, characteristics of the market, and based on its mission, strategies WGI could use to appeal to that market.

\section{Case 2: Visitor Elite}

This week, one of TSLC's founders introduces you to your next client, an entrepreneur who grew up in San Antonio: "Zane Lumpkin formed Visitor Elite two years ago as a service 
company that packages high-end sport spectator experiences for travelers who visit Dallas for business. Zane is on the verge of making a decision that could pull the company away from its foundation. Compounding the problem is his team. They are all over the place on this one. I think the company needs some help before they run out of time."

Background. Zane Lumpkin grew up as a fan of the San Antonio Spurs. His father was a blue-collar worker who always commented about what it would be like to sit in the skyboxes. "Those are the real high rollers!" his father would always say. "Those people have the money, the connections, and the bar service!" Usually he would say that last part as he shook his empty beer cup and stood up to head for the concourse. Zane couldn't help but become fascinated with those prime seats as well.

Zane attended a local liberal arts university, studying sport management with his old friends from South San High School, Joaquin and Erica. Although it was Zane who managed to get the first job at the AT\&T Center, his friends were not far behind. During his three years there, Zane spent as much time as possible working guest services in the luxury suites. Eventually, he convinced his friends that there was an opportunity in this space for them - not as typical service personnel, but as providers of more than just the skybox experience. The idea for Visitor Elite was born.

The concept was to provide and extend a skybox experience by including dining, transportation, and other entertainment around the sport event. The Spurs did not have any skyboxes available at the time, but the owner thought it was an intriguing idea and that the Dallas Mavericks might be interested in this type of arrangement... for a cut of course. A few tense phone calls and meetings later, they had a deal. The Mavericks would allow this business arrangement on a trial basis for two years. 
The business evolved quickly as they established it. Larry, a Dallas local, joined the team and quickly expanded the entertainment options to span multiple days, with side trips including hunting exotic animals and gambling in Oklahoma. Joaquin found that selling the packages specifically for out of town guests gave local business people the leverage they needed to use their corporate accounts. Erica set up the internal operations and hit on the successful idea that the packages could be auctioned during the week before the game. Zane held the whole operation together including the original staff, the new hires, as well as managing the relationship with the Mavericks. The original friends viewed Zane as the center of the organization and the new team members quickly picked up on this.

Visitor Elite has a skybox along with its 15 season tickets at American Airlines Center, home of the Mavericks. These tickets are packaged with transportation, entertainment, and hosting services and sold to local companies for the express purpose of entertaining visiting clients or associates. The packages are sold through a bidding process held the week before each home game. The attendees must include at a minimum 10 people from out of town. Since implementing the current bidding format they have not failed to sell the packaged deals (of course, playoff-level play by the Mavericks didn’t hurt either).

The challenge. The Visitor Elite staff is now itching to expand. Joaquin is after Zane to contact the Spurs and pursue the same arrangement back home at the AT\&T Center. Larry is happy with Dallas and believes the way to go is to look to the Texas Rangers or the Dallas Stars for expansion. Erica believes that the way to go is to create more packages that would appeal to a predominantly female market to increase the types of customers they get to serve and the number of companies bidding. More than one meeting on this subject has ended with team members becoming more deeply entrenched into their positions with no resolution in sight. 
Zane is a little unsure of what to do. During a trip back to San Antonio, Zane took his father to the Spurs game and even got them into one of the corporate skyboxes through a contact. He watched his father enjoy his first game among "the real high rollers," and he also thought about how his father might never again get the opportunity to sit in one of these seats.

That night Zane wrote a short email to his friends. It said, "We have been in the business of facilitating the entertainment of the richest of the rich, funded by the corporate bank accounts which are filled with money from our families. I don't know how much longer I can do it. I thought this company would be adding to the world of sport that my father taught me to love. I'm not sure that it has ever done that. I'm not sure that I want to renew the contract with the Mavericks."

When Zane got back to Dallas he headed into the office for the Monday meeting. Erica caught him in the hallway. "I understand where you are coming from. I have gotten really tired of these fat-cats partying on someone else's dime. That is one of the reasons I brought up the packages for women."

During the meeting, Zane and Erica didn't say much. Larry did most of the talking, yelling really. He went on and on about the sweet thing they had going, the money they were making, and the great golden road ahead. He also mentioned how Zane could "screw it all up with one wrong comment to the Mavericks!" Joaquin also thought that a change right now would be unwise. They have developed a good thing and although they might want to change it in the future, they should ride it out for now. Just as in the past, during the meeting the three treated Zane as the de facto leader of their group. 
The meeting with the Mavericks to plan a strategy for the next two years is scheduled for Thursday. That only gives Zane a few days to figure out how to get his team unified around a new proposal in time to meet the deadline.

Your task. Your group will need to help Zane get his team to work together to prepare a cohesive plan to present to the Mavericks. During this turbulent time for Visitor Elite, Zane needs the leadership team to work together throughout the year. The lack of official roles for members of the leadership group will complicate any solution. Even Zane does not hold an official title - only informal recognition as a leader of the leaders. Your recommendations to Zane should consider current leadership theory. It could be based upon the Hill Model for Team Leadership or Lencioni's “The Five Dysfunctions of a Team.” Specifically, you should provide concrete steps for how the Visitor Elite leadership team can reestablish cohesion, trust, and a focus on developing a common goal.

\section{Case 3: Two ADs and an Intern}

At this week's meeting, one of the TSLC introduces a new client: "Our next project is to help out a couple of local Athletic Directors. This past Monday evening I overheard their conversation down at Goodtime Charlie's; great burgers, and their chicken fried steak is awesome! Anyway, the place was full of several ADs, coaches, and even interns, talking about their work environments. Eventually most of the people paid and left for the evening. Only two ADs and an intern remained of the large group. I couldn't help but offer to help them out.

Background. Ricky, Bobby, and Wayne had just spent the day at a trade show featuring the latest in equipment at the Convention Center. Ricky and Bobby are both new Athletic Directors of Division II college programs, where the University's leadership wants to move to 
Division I in the next few years. Wayne is an intern at a local 6A high school program. The first six months have not been what Ricky or Bobby had hoped they would be.

Ricky led the complaining with, "I can't believe how lost these people are. Every day I have coaches and administrators coming into my office asking what I want. I am so sick of people asking the question, 'How are we going to win a championship?' If they would pay attention for one minute, they would know that I just talked to them about it! For example, last week I was watching the cross country coach work with his team. I noticed he was droning on and on about the team strategy for meets this season. After practice I told him that he didn't seem to be a leader when he was talking to them like this. He didn't seem like a leader at all. A coach should inspire his athletes. They should see it in him or her. The coach should radiate something worth following."

"I've found that just being yourself is the ticket to leadership. Followers will see in you what they want to be. That is how I got where I am today. I don't spend my time making elaborate plans for everyone else. I am an idea man. The coaches can get it done if they just take a few of my suggestions about leadership and how to influence and inspire athletes."

Ricky went on to talk about his situation. Apparently, the coaches constantly complain that he is not providing any leadership. They seem to feel that the ship is without a captain. Ricky, however, believes that the problem is that they don't spend enough time with him. When he was a head coach at his last job, all of the assistant coaches and athletics staff were around him every day. They could see what he was about and follow his lead. He doesn't want to handhold all of these coaches through every problem. To be honest, Ricky admits that he doesn't like to tell people what to do. These coaches are experienced enough to get the job done. The previous AD had been there forever and seemed to be a real micro-manager. Ricky solves his 
own budget problems. The coaches should stand up and solve their own budget problems. He feels he has created a system that empowers them to get the job done, but they don't seem to be taking ownership in the way he expects..

Bobby spoke next: "I don't have a problem with my coaches and staff being lost. I have a problem with insolent coaches disregarding my plans. Twenty years in the U.S. Army taught me one thing and that is you can never plan enough. Murphy's Law will let you know about the quality of your plans; your main plans, your contingency plans, and your 'holy-crap' plans. My staff and coaches are obviously not used to thinking very far ahead. When I tell them to plan out the next several seasons, they look at me like I am sending them to their rooms without dinner. Little kids! I have given them my department business plan for the next five years complete with several contingencies for things like boosters getting us in trouble, drastic budget cuts, or a natural disaster taking out our key facilities. I have laid out the road to multiple championships within five years in the plans."

"I catch them talking behind my back like four year olds. One time, my head volleyball coach was complaining to the financial aid staff when I walked up behind them. I overheard her say that I was 'an uptight drill sergeant that needed a weekend in Nuevo Laredo to either loosen up or get kidnapped. No preference.' You know, it is one thing to be grumpy about something in the department, but it is another totally to air dirty laundry to someone outside of the unit. Believe me when I tell you that I gave the volleyball coach an earful when we got back to the office."

Bobby continued to tell more stories about how the athletic department had struggled for years before he got there. The university president told Bobby that he has extensive latitude to get the job done. He was just short of starting to fire coaches who were not on board with the 
new demands under his leadership. He was considering this for his new mantra: "Put up and shut up or get out!" Still, he realized that resorting to that philosophy would be a shame. There are several coaches who have gotten some good results in the past, but Bobby has yet to figure out what they are doing. They don't seem to have any rhyme or reason for what they do. If they have a plan from one day to the next, he can't see it. "Recruiting plans are vague and yearly budgets are like skeletons - nothing fleshed out."

The Challenge. Wayne, the intern, didn't say very much for most of the evening. Near the end he pipes up with, "I haven't had that much trouble with my athletic department. The AD there can be hardheaded sometimes, but lately I've gotten him to adopt several of my ideas about how to make the program better." The two ADs seemed a mixture of stunned and unimpressed. He continued, “See, the trick is to begin with yourself. Master yourself first. I don't just react to my AD, I choose my own actions.”

"Once you get a handle on yourself then you can really begin to work with others. I try very hard to understand the others in my department and what we can achieve together. I always look for solutions to problems that benefit all of us. You guys hear about the new coordination project between the city parks and recreation department and my school district? That was my idea." The coaches, still not speaking, nodded in unison. "It tripled the number of practice fields available to us. It required us to open our fields up to the parks people and shift attitudes beyond people's comfort zones, but in the end it worked out for everyone." With that, Wayne checked his watch, stood up to leave and said, "Good luck with your programs," as he walked away. Ricky and Bobby said it at the same time, "Punk!" That was followed by, "What the hell could he know?" and "Still wet behind the ears." These comments didn't last very long until both fell silent. The two were deep in thought. The glances toward the now empty chair showed what 
they were thinking, 'That couldn't be true. He couldn't have turned that school district's facilities problems around so drastically, so quickly.'

I saw the moment to land two new clients and said, "I think I know what your friend was talking about." I moved over to their table and took Wayne's vacant seat. "But first, let me tell you about Sport Leadership Consultants.” So, we have our next client!

Your task. It is evident based on the story relayed by the TSLC founder that these two ADs have leadership styles which poorly match the needs of their staffs and central challenge: transformation into an NCAA Division I level program. You will need to provide a plan that considers the pressures to manage and lead during a time of transition as well as how to resolve issues caused by uncalibrated leadership styles. Before making the final recommendation, your group should discuss the importance of matching leadership style to a followers needs. Specifically, the proposal should include details about how Ricky and Bobby can employ the Situational Leadership Model. Additionally, prepare to explain why Ricky and Bobby should better understand themselves before trying to lead others.

\section{Case 4: The Frackers}

This week, one of our TSLC founders has another new client to introduce to us. She begins, "This week we are going to help a small team in trouble. The general manager for the local Texas minor league hockey team, The Frackers, has to figure out what to do next. Her team is in the middle of a crisis smack dab in the season ticket renewal period. She is a very experienced professional, but thinks she might be too close to the problem to see it effectively. I said not to do anything until one of my teams arrived."

Background. Holly Demming has been a fan of hockey since she was able to cheer with her dad. Their season tickets on the glass were one of the best parts of her growing up. The 
rumble of the crowd, the slice of the blades over ice, and the physical shock wave that came when a player was checked hard in the glass right in front of her; early on she knew she had to be part of this sport. The total knee blowout during the 1996 Minnesota High School playoffs changed her course from being on the ice to running the show from the front office.

A little over three years ago she got the call she had been waiting for; she was given the reigns to The Frackers, a Texas-based minor league franchise associated with the NHL team she had been working with for over 15 years. This was her chance to not only set up her career for a front office leadership job in the NHL, but to make a real contribution to the sport she loved and to the fans who have become her extended family. During every game she scans the glass to see if there is a young version of herself learning to love the game. Whether she sees her or not, Holly strives to never disappoint that little girl.

Holly views season ticket sales as a prominent marker for the team's success. For her, season tickets represent the highest level of fan commitment and renewal is the most telling indicator of fan satisfaction. The community connected with the team's launch and the 1,000 season tickets sold out. At the end of the first season, the churn was nothing out of the ordinary for a first season team -- 500 season tickets renewed and 500 dropped. The team did sell the open season tickets to have all 1,000 seats filled. Interest surveys showed they always have about 500 people interested in getting season tickets if they are made available. Holly made a point to keep her sales people aware that even though they had 1,000 season ticket holders and 500 more waiting for a chance to get one, they also had 500 people who had chosen not to renew.

Complications. Now as the season draws to a close, and season ticket renewal season is around the corner, the wheels seem to have come off the bus. On Monday, the Public Relations Director, Alvin Alleman, and the Zamboni driver, found head coach, Vladimir Olishkivinsky in a 
fist fight with the team's star player, Jean-Philippe Martin, in the parking lot outside the team locker room. Although no photos or video of the incident have surfaced, two fan blogs associated with the team lit up with people claiming to have seen the fight. Holly suspects that the Zamboni driver must be the eye-witness posting on the blogs.

Actually, trouble has been brewing at the Frackers for a while. Olishkivinsky is slowly losing his luster with the fans. Two straight seasons with a losing record is starting to take the shine off of his great successes, which includes two league championships during his nine years at the helm. He is still mostly beloved by the fans, but there is a growing sentiment that his best years are behind him.

One person that isn't slow to point out that the coach should go is Jean-Philippe Martin. The French-Canadian has loudly criticized the coach during press conferences, during player appearances at local schools, in the night clubs, and anywhere else that someone will listen. Martin believes that the coach is the reason his "extraordinary talent" (his words) isn't used to its potential. He laughs when he hears the coach say the problem is that Martin refuses to play by the team philosophy. "I have the winning philosophy. It is... give me the puck."

Alvin Alleman doesn't agree. The long-time PR director complains almost daily about Martin's behavior. The fights in the club, the negative comments to the press; he isn't sure that any coach would fare better with a loose cannon like Martin. "Give him a victory over the coach and you will have just sold your soul to the devil."

Holly has tried to read the Frackers' fans and they seem to be hesitant to commit to another season with so much up in the air. They seem hungry for more information from the organization before they are willing to renew. The sales department has taken the almost fullstop of season ticket sales as a doomsday prophecy. She overheard one saying "Game over dude! 
We have to go on the offensive. We treat every sale like a one-time opportunity; like a shop owner when the cruise ship comes in, you only have one chance, and it is hard sell all the way. A.B.C. baby - Always Be Closing! Except after all of these pigs are sold, I am the one getting on that ship and sailing off into the sunset." That sounds to Holly like a perfect way to destroy whatever goodwill remains with the fans.

In her heart Holly knows that Coach Olishkivinsky and Jean-Philippe could each hold the key to the future success of the organization. This scandal will eventually blow over, but maybe not before doing some serious damage to the organization and her career. Holly also knows that the season ticket sales are a major key to surviving these troubled times with her career intact. The home office in the NHL is watching and knows that the long-term success of the team will be indicated by this fan group's relationship to the organization. Support with their wallets is often accompanied by their support within the community, local government, and press.

Your task. Holly has scheduled a meeting tomorrow at noon with the head coach, the star player, and the public relations director to find some solution for this crisis and conflict. She is going to need a plan. Specifically, you need to provide Holly with a diagram detailing the power dynamics of the principle case figures. Additionally, help her consider the meeting logistics. How should the room be arranged? Should she pre-arrange seating? Why or why not? What information from your previous experience could help with your suggestions to Holly? 